\title{
O PODER DOS CIDADÃOS NO PARADIGMA INTERSUBJETIVO HABERMASIANO
}

\author{
Marilucia Flenik $^{1}$
}

\begin{abstract}
RESUMO: O presente artigo busca em Jürgen Habermas elementos que repercutem na democracia, situando o cidadão como detentor do poder que legitima o direito. Seu objetivo é esclarecer a mudança do logocentrismo para o espaço discursivo da linguagem. Sua democracia é procedimental, no sentido de que se deve garantir os pressupostos do discurso. A metodologia utilizada foi pesquisa bibliográfica, com a compilação de conceitos do referencial teórico de Habermas, pontuando a sua contribuição para o esclarecimento da ruptura da tradição e o mundo discursivo contemporâneo, com os seus reflexos no avanço da participação dos cidadãos na construção da democracia.
\end{abstract}

PALAVRAS-CHAVE: Democracia; Intersubjetividade; Discurso; Poder; Cidadania.

\section{THE POWER OF CITIZENS IN THE HABERMASIAN INTERSUBJECTIVE PARADIGM}

\begin{abstract}
This article seeks in Jürgen Habermas elements that reverberate in democracy, placing the citizen as the holder of the power that legitimates the right. Its purpose is to clarify the change from logocentrism to the discursive space of language. Its democracy is procedural, in the sense that one must guarantee the presuppositions of discourse. The methodology used was a bibliographical research, with the compilation of concepts from the theoretical reference of Habermas, punctuating its contribution to the clarification of the rupture of the tradition and the contemporary discursive world, with its reflexes in the advance of citizen participation in the construction of democracy.
\end{abstract}

KEYWORDS: Democracy; Intersubjectivity; Speech; Power; Citizenship.

\footnotetext{
${ }^{1}$ Doutora e Mestre em Direito Socioeconômico e Ambiental pela PUC/PR. Especialista em Filosofia Moderna e Contemporânea pela UFPR. Professora do Curso de Direito das Faculdades Integradas do Vale do Iguaçu UNIGUAÇU. Mediadora Extrajudicial e do CEJUSC da Comarca de União da Vitória e Advogada.
} 


\section{INTRODUÇÃO}

O presente artigo pesquisa a influência exercida por Jürgen Habermas na Filosofia do Direito no que tange a busca de uma compreensão pelo novo paradigma da linguagem, que situa o debate discursivo da legitimidade do poder dos cidadãos no âmbito do espaço público da política democrática.

A pesquisa apresenta como objetivo esclarecer a ruptura da tradição filosófica através da descrição do macro-paradigma da linguagem, conforme descrito por Habermas, que se filia a virada linguística pragmática. Mediante uma pesquisa bibliográfica, identifica os pontos relevantes apresentados por Habermas, para traçar um pensamento pós-metafísico, ínsito da contemporaneidade e apto a explicar a participação dos cidadãos no poder de república democrática.

Três linhas de argumentação são traçadas, sendo que a primeira aborda a linguagem como um macro paradigma filosófico, com a superação do logocentrismo para o espaço intersubjetivo. Na segunda linha aborda-se o pensamento pós-metafísico e a virada linguística pragmática, situando Habermas a razão e a vontade como elementos para inverter a primazia da teoria sobre a práxis social. O ser humano se constitui pela linguagem sendo esta fator de entendimento do mundo da vida. A teoria da ação comunicativa desenvolve o paradigma intersubjetivo da linguagem e a verdade deixa de ser anunciada a priori pelo sujeito, para resultar do debate discursivo, travado pelos sujeitos capazes de falar e agir. A teoria do discurso de Habermas propõe as condições para a disputa permanente sobre questões de princípio tanto em matéria de Moral, como de Direito, objetivando um acordo discursivo.

A terceira linha aborda justamente essa capacidade dos cidadãos para exercer o poder que lhes pertence de direito, o poder de legitimar o ordenamento jurídico do Estado Democrático de Direito.

Espera-se contribuir para o esclarecimento de como é possível o surgimento do espaço público, tal qual descrito por Arendt, aquele do poder dos cidadãos, que traçam as normas de conduta que serão chanceladas pelo Direito. Habermas criou um tipo de política deliberativa, que encontra no Direito o instrumento adequado à sua implementação. Traz para o mundo empírico e social o problema de quais regras os cidadãos querem estabelecer pelo meio do Direito. O conteúdo será aquele acordado pela comunidade discursiva. Para a democracia 
procedimental são importantes as regras estabelecidas juridicamente e que garantem a possibilidade de concretização do debate discursivo. O social passa para o primeiro plano e tal reviravolta marca profundamente o novo paradigma da razão comunicativa, que procura dar conta da participação política dos cidadãos na construção do Estado Democrático de Direito.

A metodologia adotada foi a pesquisa bibliográfica, que trouxe as colocações de Habermas e Arendt a respeito do efetivo poder dos cidadãos, capazes de falar e agir e recriar a democracia em novas bases, uma vez que a época atual permite uma maior comunicação.

Esse modo discursivo de socialização tem que ser implantado através do Direito Positivo, que serve para reduzir a complexidade social. A institucionalização dos processos decisórios, como a regra da maioria, os órgãos de representação, a transmissão de competências de decisão, e outras medidas, visam garantir a formação da opinião e da vontade coletiva. A política deliberativa conduz à democracia procedimental no sentido de que havendo regras que garantam a liberdade de expressão, compete aos cidadãos a co-responsabilidade na formulação dos direitos e deveres respectivos. Democracia e direitos humanos são co-originários, levantando-se a questão de que é tempo de uma evolução no sentido de aperfeiçoar o modelo político representativo, podendo os cidadãos adquirirem maior espaço de visibilidade nas decisões políticas.

\section{A LINGUAGEM COMO MACRO-PARADIGMA FILOSÓFICO}

Habermas denuncia a ruptura da tradição filosófica ocidental, questionando quatro temas principais, que figuram como eixos de sustentação de um novo paradigma filosófico, centrado no caráter intersubjetivo da linguagem. São palavras-chaves dos seus questionamentos: o pensamento pós-metafísico, a viragem linguística, a situação da razão e a inversão da primazia da teoria sobre a prática, ou seja, a superação do logocentrismo. (HABERMAS, 2002)

O pensamento pós-metafísico pretende superar tanto o paradigma ontológico, como o paradigma da consciência, buscando na linguagem uma nova forma de conceber o ser humano e sua maneira de apreender/compreender o mundo, formulando novas perguntas na área da filosofia, cujas possíveis respostas refletem diretamente na área do Direito.

O conceito de razão comunicativa surge como verdadeira revolução, capaz de alterar o paradigma da modernidade, tal qual Kant (2003 ) o fizera, quando centrou no sujeito pensante 
tanto as condições epistemológicas do conhecimento, como as possibilidades da razão prática do sujeito singular alcançar os padrões universais da moral. Agora o sujeito abstrato cede lugar aos indivíduos empíricos, que interagem a fim de estabelecer o que é o certo para si mesmos. A pragmática linguística revolucionou a filosofia da consciência, criando novas categorias de verdade e objetividade, realidade e referência, validade e racionalidade. Afirma Habermas que “a análise lógica da linguagem ganha sua envergadura filosófica pelo fato de o paradigma da linguagem substituir o da consciência e revolucionar os fundamentos mentalistas” (HABERMAS, 2007 p. 78). Com a destranscendentalização, operada pela viragem linguística pragmática, o sujeito abandonou o reino dos seres inteligíveis para mergulhar no mundo da vida articulado linguisticamente pelos sujeitos socializados, que precisam das regras do Direito a fim de possibilitar a própria convivência.

\subsection{O PENSAMENTO PÓS-METAFÍSICO E A VIRADA LINGUÍSTICA PRAGMÁTICA}

Caudatário que é do pensamento de Wittgenstein, a partir do momento em que ele descobriu o caráter de ação dos enunciados linguísticos como jogos de linguagem, (HABERMAS, 2004a, p. 121), a mediação entre a teoria e práxis forma o núcleo da sua teoria. São principais características da pragmática linguística o anticartesianismo epistêmico da relação sujeito/objeto e a ideia do falibilismo que acompanha a compreensão histórico-social do saber. No que tange a primeira questão, quebra-se a noção mentalista de que a objetividade é assegurada quando o sujeito da representação se refere a um objeto de forma correta, controlando o sujeito cognoscente a subjetividade de suas representações pelo mundo objetivo. Para o autor, na concepção linguística a subjetividade das opiniões não é mais diretamente controlada pela confrontação com o mundo, mas por um acordo público, alcançado na comunidade de comunicação.

Após a virada linguística, todas as explicações partem do primado de uma linguagem comum, passando a autoridade epistêmica para a práxis de justificação. A pragmática linguística trabalha com novas categorias de verdade e objetividade, realidade e referência, validade e racionalidade. Um novo paradigma foi desenhado, sendo que a razão comunicativa distingue-se da razão prática por não estar adstrita a nenhum ator singular nem a um macrossujeito sociopolítico. O que torna a razão comunicativa viável é a possibilidade das pessoas se entenderem sobre algo no mundo, utilizando uma linguagem natural, aceitando 
determinados pressupostos, a fim de que a comunicação chegue a bom termo. Uma língua não é propriedade privada de um indivíduo. Ela surge no contexto de sentido intersubjetivamente partilhado, corporificado em expressões culturais e práticas sociais. "No nível fenomênico, cada língua se desenvolve apenas socialmente, e o homem só se compreende a si mesmo ao testar, tentativamente, a compreensibilidade de suas palavras junto a outras pessoas.” (HABERMAS, 2007 p. 67)

Apoiado em Humboldt, afirma Habermas que a semântica considera a linguagem como o órgão formador do pensamento, uma vez que a realidade, no sentido de totalidade de objetos suscetíveis de descrições, resulta da interpretação dos sujeitos cognoscentes. Na conversação, que por assim dizer é o cerne da linguagem, os participantes querem se compreender mutuamente e ao mesmo tempo se entender a respeito de alguma coisa, ou seja, alcançar, se possível, um acordo. Cabe à pragmática o papel de realçar os aspectos universalistas do processo de entendimento mútuo. (HABERMAS, 2007 p. 69).

Nesse sentido, na pragmática formal, os sistemas gramaticais de referência são como uma moldura, de conteúdos não definidos, para a referenciação, tanto a objetos possíveis, a respeito dos quais se enunciam os fatos, numa atitude objetivadora, como para as relações interpessoais e normas prováveis, para as quais se reivindica a força obrigatória do reconhecimento intersubjetivo. Neste último caso, as pessoas que desejam vencer uma realidade recalcitrante devem assumir uma atitude performativa a fim de chegar a bom termo, alcançando o entendimento mútuo. Desta forma, o uso comunicativo da linguagem permite a construção de um espaço público de um mundo da vida intersubjetivamente partilhado pelos usuários da linguagem. Aqui ocorre o entrelaçamento das operações cognitivas com os processos de cooperação e entendimento mútuo dos indivíduos socializados.

Com a virada pragmática da linguagem promovida por Habermas, o eu da filosofia da consciência, que mediante a representação se apropria do conhecimento e formula as suas convicções, cede lugar para a visão alargada da intersubjetividade da interação humana, diante da qual o sujeito precisa justificar suas concepções. Trata-se de uma abordagem pragmática da linguagem, considerando as manifestações linguísticas como atos de fala, pelos quais um locutor quer entender-se com outro sobre algo existente no mundo.

2.2. A SUPERAÇÃO DO LOGOCENTRISMO, A SITUAÇÃO DA RAZÃO E A INVERSÃO DA TEORIA SOBRE A PRÁTICA 
Marilucia Flenik

A tradição analítica se fundamenta na posição empirista de Hume (1995), em que o dado da experiência tem primazia sobre o constituído, existindo apenas entidades concretas e particulares, em posição distinta a atitude nominalista que considera as entidades abstratas como ideias universais e necessárias. No entanto, além da realidade ou mundo objetivo, há um mundo social e um mundo interior ou subjetivo, que proporcionam os referentes dos atos de fala, os quais são usados para descrever o mundo objetivo (HABERMAS, 2004, p. 167).

Na proposta habermasiana, o sujeito prático kantiano abandona a individualidade do encantamento com o "céu estrelado" acima de si e a confiança da "luz moral dentro de si" (KANT, 2002b, p. 255), para enraizar as condições de possibilidade da racionalidade nos sujeitos situados no tempo e no espaço, capazes de falar e agir, quando se revelam a si mesmos e também descobrem a objetividade de um mundo que se manifesta pela intersubjetivade do discurso (HABERMAS, 2002 p. 39-40).

O salto para o novo paradigma da linguagem consiste justamente no enfoque dado à intersubjetividade. Não mais as normas ditadas pela consciência solipsista do sujeito prático kantiano, mas sim as normas acordadas mediante o discurso. Habermas faz uma releitura de Kant e abandona a distinção de ordens distintas, um mundo sensível, dos fenômenos, e outro inteligível, criado pela razão para se pensar a si mesma como prática, ou seja, como liberdade, capaz de descobrir os princípios subjetivos das ações, isto é, as máximas, verdadeiros princípios que valem objetivamente e informam uma legislação universal que obriga a todo o ser racional, como um imperativo categórico.

A genealogia do agir comunicativo ou da argumentação reflete uma destranscendentalização da razão, que parte de Kant e conduz à concepção de um pragmatismo kantiano. Recorda Habermas (2004, p. 17) que a pragmática da teoria do conhecimento de Richard Rorty modificou o questionamento transcendental de Kant, sobretudo quanto as premissas básicas idealistas, quanto ao modo a priori de conhecer, que remete os conceitos a uma região abstrata, subtraída do tempo. Agora as condições transcendentais não são mais condições necessárias do conhecimento (HABERMAS, 2007, p. 18).

O a priori do sentido suposto pelas visões linguísticas do mundo deve apresentar-se no plural e perder a validade universal de um a priori transcendental. Estruturada por uma língua, a pré-compreensão do mundo como um todo é, antes, a priori arbitrária e indiferente, mas $a$ posteriori necessária e indispensável. “A análise do uso linguístico orientado pelo entendimento 
mútuo, feita na perspectiva dos participantes, fornece a chave para a rede das práticas do mundo da vida como um todo.” (HABERMAS, 2007 p. 25).

No lugar da certificação autorreflexiva de uma subjetividade ativa in foro interno, para além do espaço e tempo, entra a explicação de um saber que é de natureza prática e habilita sujeitos capazes de falar e agir a participar de tais práticas privilegiadas e a realizar operações correspondentes. Não se restringe apenas a juízos empíricos, mas abarca as proposições gramaticais, os objetos geométricos, os gestos, os atos de fala, os textos, as contas, os enunciados, as ações, as relações ou interações sociais. Trata-se, portanto, em geral, de tipos elementares de comportamento regido por regras. Afirma Habermas que "o sujeito cognoscente está sempre junto a seu outro. Nosso saber a respeito do mundo objetivo é de natureza social.” (HABERMAS, 2004, p. 185).

A partir das gramáticas de jogos de linguagem e formas de vida, a consciência transcendental se socializa e se diversifica ao mesmo tempo. Ocorre, uma inversão da tradicional primazia da episteme sobre a práxis. Da perspectiva pragmática a linguagem deixa de ser uma simples relação dupla entre expressões simbólicas e seus objetos de referência, para ser verdadeira comunicação que se estabelece mediante uma tripla relação entre sujeitos racionais, linguagem e mundo.

\subsection{A LINGUAGEM COMO FATOR DE ENTENDIMENTO E O MUNDO DA VIDA}

O novo paradigma da linguagem reconhece que os indivíduos socializados encontram na linguagem o fator de entendimento que possibilita a construção e a manutenção das ordens sociais. A filosofia da consciência sempre privilegiou o íntimo, o lado interior da pessoa humana, relegando a um segundo plano o lado social, exterior ao indivíduo. A teoria do conhecimento, por sua vez, colocou a comunicação e o agir na esfera dos fenômenos, permanecendo como secundários diante da mente especulativa. Com a filosofia da linguagem ocorre uma inversão nessa hierarquia, uma vez que a linguagem é utilizada não apenas na representação, mas, sobretudo, na comunicação. Os proferimentos linguísticos tanto são fontes do conhecimento como também servem para o estabelecimento das relações interpessoais (HABERMAS, 2007, p. 9). Desta forma, ocorre a destranscentalização dos sujeitos cognoscentes, que não encontra outro apoio de sustentação para o seu entendimento, que não as próprias regras do discurso, inclusivo para todos.

A partir da virada linguística o conhecimento se desloca do sujeito capaz de representação dos objetos, para uma atitude reflexiva com relação aos proferimentos da 
comunidade discursiva. O diálogo deixa de ser interior, para se projetar diante da validade problemática dos proferimentos intersubjetivos, sendo que a interioridade do sujeito se constitui pelo viés da comunicação.

A fim de delinear o novo paradigma filosófico da razão comunicativa, Habermas acentua que a linguagem é o veículo de incorporação da razão, uma vez que o espaço do discurso racional, travado em âmbito intersubjetivo, é o local viável de justificação. Resgata diversos conceitos kantianos, e busca na ideia cosmológica da unidade do mundo, a mesma suposição pragmática de um mundo objetivo comum, que permite um entendimento a priori, decorrente da linguagem comum. Adota a ideia da liberdade kantiana, como um postulado da razão prática, o que faz a pragmática da racionalidade supor que os atores são responsáveis por seus proferimentos e, por isso, imputáveis. Aceita também a capacidade da razão, que transcende todo condicionado na direção de um incondicionado, o que permite a incondicionalidade das exigências de validez levantadas no agir comunicativo. Desta forma a razão comunicativa permanece com a capacidade de elaborar princípios norteadores de todos os direitos e de todas as exigências necessárias ao entendimento da comunidade discursiva (HABERMAS, 2002, p. 38).

Igualmente, a capacidade de intuir as noções existentes no senso comum, a mentalidade alargada kantiana, o colocar-se no lugar do outro, também é mantida pelo autor, uma vez que a diferença entre mundo e mundo interior, significa que o "sujeito transcendental perde sua posição do outro lado do tempo e do espaço e se transforma nos diversos sujeitos capazes de linguagem e ação” (HABERMAS, 2002, p. 38). O caminho da destranscendentalização conduziu os sujeitos que interagem para o centro do mundo da vida. Aqui impera o princípio do falibilismo e a “verdade” é aquela encontrada mediante o princípio do discurso e que almeja apenas a justificação convincente do melhor argumento. Abandona-se as categorias do entendimento e formas de intuição apriorísticas. No lugar do idealismo transcendental, que concebe a totalidade dos objetos experimentáveis como um mundo para o sujeito, surge um realismo interno, no qual, segundo Habermas, é real tudo que pode ser representado em expressões verdadeiras, no fórum do discurso racional, no qual bons fundamentos devem ostentar sua arte de convencer (HABERMAS, 2002, p. 41-44).

A diferença fundamental entre a razão prática kantiana e a razão comunicativa, consiste no fato de que esta última não é uma fonte de normas do agir como pretende ser a primeira. $\mathrm{O}$ que move a razão comunicativa é a linguagem comum. Os parceiros do diálogo têm como 
pressupostos apenas a significação dos enunciados e a pretensão de validade em relação a estes proferimentos surgem no momento em que os interlocutores são autônomos e verazes consigo mesmos e com os outros. A ação comunicativa não pressupõe nenhuma regra de ação prescritiva dada a priori, capaz de exercer uma coerção transcendental (HABERMAS, 1997b. p. 20).

Ser racional para Habermas significa que a pessoa pode se expressar e prestar contas de seus proferimentos, adotando uma atitude reflexiva, o que a torna uma pessoa responsável por suas palavras e seus atos (HABERMAS, 2004, p. 102). As três racionalidades parciais do conhecer, do agir e do falar convergem no nível integrativo da reflexão e do discurso e se integram mutuamente. No campo cognitivo a pessoa racional é capaz de argumentar acerca de suas próprias opiniões e convicções. Adota uma atitude orientada para fins, quer se trate de suas intervenções instrumentais no mundo objetivo, quer das relações orientadas ao sucesso, com outros sujeitos que se encontram no mundo objetivo como antagonistas.

A fim de que haja entendimento, os interlocutores supõem que todos podem compreender uma expressão gramatical de modo idêntico na variedade de situações e dos atos de fala nos quais são empregados. Os participantes da interação devem ser capazes de orientar o seu agir por pretensões de validade e a linguagem passa a ser explorada como fonte primária da integração social. Uma vez que os pensamentos se articulam através de proposições, na prática, os membros de uma determinada comunidade de linguagem têm que supor que falantes e ouvintes podem compreender uma expressão gramatical de modo idêntico. O contexto vital sociocultural surge a partir do trabalho interpretativo dos participantes mergulhados nesta interação atrelada ao mundo da vida. “O mundo como síntese de possíveis fatos só se constitui para uma comunidade de interpretação, cujos membros se entendem entre si sobre algo no mundo, no interior de um mundo da vida compartilhado intersubjetivamente” (HABERMAS, 1997B, p. 31).

Habermas (2004, p. 98) se apropria do conceito fenomenológico de mundo da vida de Husserl e o adapta para a pragmática linguística que abrange as interações mediadas pela linguagem. Para ele, o agir comunicativo se encontra inserido num mundo da vida que assegura a cobertura de um consenso de pano de fundo das convicções comuns não problemáticas. “À semelhança de todo o saber não temático, o pano de fundo do mundo da vida encontra-se presente de um modo implícito e pré-reflexivo.” (HABERMAS, 2004a, p. 103). A pessoa concreta está inserida num mundo partilhado a nível intersubjetivo, cujos mundos da vida 
habitados coletivamente se entrelaçam e se interligam. "O agir comunicativo é um processo circular, figura como produto de tradições em que se encontra inserido, de grupos solidários a que pertence, de processos de socialização e aprendizagem a que se encontra sujeito.” (HABERMAS, 2004a, p. 106). A sociedade se apresenta como mundo da vida simbolicamente estruturado a partir de mundos da vida partilhados intersubjetivamente e que constituem o fundamento da interação humana. O lugar teórico do agir comunicativo é entre o discurso e o mundo da vida. O mundo da vida forma o horizonte para situações de fala e constitui, ao mesmo tempo, a fonte das interpretações, reproduzindo-se somente através de ações comunicativas.

Segundo Habermas (2004a, p. 107) são componentes do mundo da vida os padrões culturais, as ordens legítimas e as estruturas de personalidade, textos e contextos de sentido complexos que se comunicam uns com os outros e possibilitam esclarecer como é possível a ordem social, bem como a relação entre o indivíduo e a sociedade. Trata-se de um passo adiante da filosofia do sujeito que concebeu a sociedade como um todo composto de partes, sendo que o conceito do mundo da vida rompe com esta figura do pensamento. Os sujeitos comunicativamente socializados não seriam sujeitos sem o enredo das ordens institucionais e das tradições da sociedade e da cultura. Nesse sentido, a sociedade e o indivíduo constituem-se mutuamente, uma vez que a integração social de contextos de ações é, ao mesmo tempo, um processo de socialização para sujeitos dotados de capacidade de fala e de ação que tanto se formam no mesmo processo como, por seu lado, renovam e estabilizam a sociedade, enquanto totalidade das relações interpessoais legitimamente ordenadas (HABERMAS, 2004a, p. 110).

A intersubjetividade enreda as pessoas em suas práticas comunicativas, que se referem a algo objetivo no mundo da vida e exprime a facticidade de todos os lances vividos pelas rotinas que objetivam tanto a compreensão como a ação. No lugar da subjetividade transcendental da consciência entra a intersubjetividade destranscendentalizada do mundo da vida, que abarca tanto a sociedade, como a cultura, como a própria personalidade individual. A capacidade de conhecer passa a ser analisada a partir da capacidade de falar e agir, pois as pessoas se encontram mergulhadas nas práticas do mundo da vida. A linguagem e a realidade interpenetram-se, sendo impossível um acesso à realidade não filtrado pela linguagem.

Desta maneira, a tradicional tensão entre o conhecimento teórico e a práxis, é enfrentada por Habermas, quando desloca o centro do interior da consciência do sujeito cognoscente, para o âmbito discursivo dos jogos de linguagem, espaço da intersubjetividade. Ocorre uma inversão da tradicional primazia da episteme sobre a práxis, cujo entendimento possível surge da 
dimensão da validade da linguagem. Assim, compreender uma expressão significa poder utilizá-la, a fim de se entender com alguém sobre alguma coisa no mundo.

\section{A TEORIA DA AÇÃO COMUNICATIVA E O PARADIGMA INTERSUB JETIVO}

Com a gramática dos jogos de linguagem, é tornada acessível à dimensão de um saber ligado ao mundo da vida, partilhado intersubjetivamente, que suporta as múltiplas funções da linguagem. Esta teoria considera que os atos de fala possuem uma estrutura autorreferente, uma vez que dá a conhecer a intenção do locutor, cujo significado semântico é compreendido pelo ouvinte, no sentido da utilização do que foi dito, o que significa dizer que uma pessoa faz algo ao dizer algo, sendo esta componente chamada de ilocutória (HABERMAS, 2004a, p. 82). A viragem pragmática da semântica da verdade propõe uma reavaliação da força ilocutória, tal qual definida por Austin, e coloca na componente ilocutória a sede de uma racionalidade que se apresenta como uma relação estrutural entre proferimentos, que aspiram ao reconhecimento de sua validade (HABERMAS, 2004a, p. 94).

A componente ilocutória, em Habermas, não consiste simplesmente no fato do ouvinte tomar conhecimento da opinião do agente, mas deve antes chegar à mesma concepção de que o parceiro no diálogo está convencido, ou seja, o destinatário deve aceitar a afirmação do locutor como válida. Durante o agir comunicativo o mundo da vida envolve as pessoas no modo de uma certeza imediata, a partir da qual vivem e falam diretamente, sendo uma presença de pano latente e imperceptível, que tudo perpassa. Desta forma, a racionalidade tem menos a ver com a posse de saber do que com a forma como os sujeitos dotados de capacidade de fala e de ação empregam o seu saber. O modo de utilização deste saber decide o sentido da racionalidade, pela qual se mede o êxito da ação. Isto porque o ato de fala se apresenta como uma pretensão de validade criticável, e seu locutor é capaz de aduzir razões para a sua validade. Simultaneamente, o ouvinte conhece as condições de aceitabilidade e pode se manifestar dizendo sim/não, pois é desafiado a uma tomada de posição de motivação racional diante do proferimento.

Mediante atos de fala, com força ilocucionária, os sujeitos livres e iguais coordenam a ação que institui o seu modo de viver. Isto porque o êxito ilocucionário de um ato de fala se mede pelo reconhecimento intersubjetivo que a pretensão de validade levantada por meio dele encontra diante dos interlocutores que assumem, a cada vez, os papéis de falante e de ouvinte, quando se comunicam no nível de entendimento mútuo. “A força ilocucionária se obtém se o 
ator anuncia suas intenções numa situação de comunicação, ou seja, se as manifesta com o objetivo ilocucionário de que os outros levem a sério suas intenções e contem com sua execução.” (HABERMAS, 1997a, p. 111).

No contexto do agir orientado para o entendimento, surge a suposição de racionalidade, a significar que um sujeito agindo intencionalmente deve estar em condições de explicar as razões do seu agir perante a comunidade discursiva. Não basta o pressuposto de que é inerente ao ser humano a racionalidade, quebrando-se, assim, o paradigma da consciência, uma vez que a racionalidade intersubjetiva conduz ao entendimento mútuo, posto que os interlocutores precisam chegar a bons termos uns com os outros sobre algo no mundo.

Sempre que as pretensões de verdade são problematizadas e se tornam objeto de uma controvérsia com base em argumentos, os parceiros assumem uma práxis argumentativa em que eles desejam se convencer mutuamente, aprendendo uns com os outros. "Sob os pressupostos comunicativos modificados de tal discurso racional, as opiniões, que até então pertenciam ao pano de fundo não-problemático do mundo da vida, são examinadas quanto à sua validade.” (HABERMAS, 2004, p. 92).

Habermas diferencia os níveis do discurso e do agir, no seio da comunicação com vistas ao entendimento mútuo. Daí distinguir o autor uma racionalidade orientada para fins, consistente em um saber proposicional em ações teleológicas, de outro tipo de racionalidade voltada ao entendimento, que parte da utilização comunicativa de um saber proposicional nos atos de fala. Distingue, portanto, o agir estratégico do agir comunicativo. O primeiro se revela em função do mecanismo de coordenação de ações e a linguagem natural é utilizada para a transmissão de informação, enquanto que no segundo a linguagem é fonte da integração social (HABERMAS, 2004a, p. 85). O que distingue o agir comunicativo do estratégico é a racionalidade que pode ser alcançada, na forma de um consenso que não está restrito aos fins dos planos de ação individuais. A nível do agir comunicativo os agentes abandonam o egocentrismo de uma orientação pautada pelo fim racional do êxito próprio e se submetem aos critérios públicos da racionalidade do entendimento, fundando o primado do social sobre a individualidade.

Neste tipo de socialização os sujeitos se reconhecem como responsáveis e se envolvem numa rede de relações intersubjetivas em que devem responder por si próprios uns perante os outros, fornecendo e exigindo razões capazes de justificar os respectivos pontos de vistas. A expressão “intersubjetivo”, para Habermas, significa a possibilidade de interação de diferentes 
pessoas que compartilham uma pré-compreensão linguística no horizonte do mundo da vida, em que todos se encontram antes mesmo de se entender sobre algo no mundo (HABERMAS, 2004a, p. 240). Atribui-se aos sujeitos capazes de falar e agir a autonomia para expressar a razão comunicativa que dá origem à própria socialidade e as instituições políticas, mediadas pelo Direito.

Todo aquele que pretende participar da comunidade discursiva parte de pressupostos que garantem a racionalidade do processo comunicativo em si. Os parceiros do diálogo devem atribuir significado idêntico a enunciados, devem levantar sempre uma pretensão de validade em relação aos seus proferimentos e a se reconhecerem mutuamente como pessoas autônomas e verazes consigo mesmas e com os outros, isto é, imputáveis, no sentido de serem responsáveis por suas palavras e pela própria conduta.

No modelo pragmático da linguagem a autoridade epistêmica deriva da práxis pública da comunidade linguística, ficando em segundo lugar as vivências privadas do modelo representacional do conhecimento. A passagem para este modelo comunicacional do entendimento mútuo, significa o primado do social, em que cada interlocutor mergulhado na rede de relações intersujbetivas, deve responder por si mesmo perante os outros. Essencial que os membros da comunidade dos sujeitos capazes de falar e agir se reconheçam mutuamente como sujeitos responsáveis. "Os participantes do discurso compreendem uma expressão à luz das razões que a tornam aceitável tendo em conta as condições e consequências do emprego correto.” (HABERMAS, 2004b, p. 142).

A razão comunicativa opera na base de pretensões de validade da verdade proposicional, da veracidade subjetiva e da correção normativa. Contudo, ela se refere apenas às intelecções e asserções criticáveis e abertas a um esclarecimento argumentativo, possibilitando aos parceiros a liberdade de estabelecer as normas de conduta adequadas para um tempo e espaço definido, sem quaisquer imposições de nível transcendental, dados a priori (HABERMAS, 2004b, p. 37). Os atos de fala se referem a possíveis razões e se reportam a um auditório da comunidade de interpretação ilimitada, idealmente alargado, perante o qual os argumentos devem ser justificados a fim de obter a chancela de racionais e, portanto, aceitáveis pela comunidade discursiva. Não basta simplesmente entender o conteúdo das palavras de uma proposição. Necessária é uma atitude performativa, no sentido de que o interlocutor, diante do ato de fala de outro, toma uma posição por sim ou por não, a respeito da pretensão de verdade implícita no proferimento. “Liberdade comunicativa só existe entre atores que desejam entender-se entre si 
sobre algo num enfoque performativo e que contam com tomadas de posição perante pretensões de validade reciprocamente levantadas.” (HABERMAS, 1997a, p. 156).

A visão sob o ponto de vista fenomênico dos atos de fala não se restringe apenas ao conteúdo dos proferimentos, mas leva em consideração principalmente as atitudes dos participantes da comunicação. Estas pretensões de verdade dos enunciados devem, ser apreciadas à luz das razões que os interlocutores aduzem a fim de justificar sua assertiva. A compreensão de um ato de fala é plena quanto os interlocutores conhecem tanto as condições sob as quais ele pode ser pronunciado, como quais consequências que a sua aceitação acarreta para os envolvidos na interação. Os interlocutores, desta forma, compreendem uma expressão à luz das razões que a tornam aceitável tendo em conta as condições e os resultados do seu emprego correto. Aprende-se algo do mundo mediante a interação humana. O diálogo é típico da situação em que leva os interlocutores a se entenderem sobre alguma coisa no mundo, partindo de um consenso prévio, produzido pelo encontro de tradições pessoais. "Nós somos aqueles cujas razões são obrigantes, que estão sujeitos à força peculiar de uma melhor razão.” (HABERMAS, 2007, p. 83). Cada pessoa está engastada no mundo e as suas percepções e os seus juízos se articulam na tessitura conceitual da linguagem e as suas ações se inserem nas práticas usuais. Mediante a interação, a pessoa se constitui como sujeito no relacionamento com os outros. A racionalidade não é prerrogativa isolada, mas surge no jogo de linguagem, no momento em que os participantes dão razões e as exigem uns dos outros, a fim de justificar os seus proferimentos.

\section{O PODER DOS CIDADÃOS E A DEMOCRACIA PROCEDIMENTAL}

Habermas na sua obra Direito e Democracia: entre facticidade e validade, se reporta à noção de “poder” inerente ao espaço democrático, conforme delineado por Arendt. (HABERMAS, 1997a, p. 187-188). Em oposição ao credo liberal que tem a liberdade, dita dos modernos, como a criação de um Estado mínimo, pronto a garantir os direitos subjetivos individuais, possibilitando a autonomia privada para contratar a vontade no interior do modelo econômico da sociedade capitalista, Arendt desenha um novo tipo de democracia em que o poder encontra-se nas mãos dos cidadãos. "É o poder que mantém a existência da esfera pública, o espaço potencial da aparência entre homens que agem e falam.” (ARENDT, 1998a,, p. 212). A verdadeira política democrática depende do poder que surge entre os homens no espaço público e prescinde da força, porque é calcada no discurso e na liberdade de ação. 
A teoria habermasiana da democracia parte da tensão entre facticidade e validade do Direito, a significar a facticidade social das promessas políticas do regime democrático, que surgem concomitantemente com a validade das normas, cuja legitimação depende da vontade popular. O autor busca nas ciências sociais os conceitos necessários para demonstrar que as práticas democráticas podem ser legitimadas através de uma descrição empirista, na visão ex parte populi, ou seja, sob o ponto de vista dos cidadãos. Para a democracia, "a ideia de uma dominação das leis, que se concretiza historicamente na ideia dos direitos humanos e da soberania popular, passa a ser vista como uma segunda fonte de legitimação” (HABERMAS, 2003b, p. 153).

O autor concebe o "poder político como uma forma de poder social abstrato e duradouro, que permite intervenções no poder administrativo, isto é, nos cargos organizados de acordo com as competências.” (HABERMAS, 1997a, p. 11). E, ainda, “o poder político só pode desenvolver-se através de um código jurídico institucionalizado na forma de direitos fundamentais” (HABERMAS, 1997a. p. 171). Portanto, o “poder” político dos cidadãos e o “poder” das leis são correlatos, sendo que a “autodeterminação democrática dos cidadãos, se concretiza mediante o Direito, havendo duas fontes de legitimação: a ideia dos direitos humanos e da soberania popular, o que levanta a questão sobre a relação entre o princípio democrático e o Estado de direito.” (HABERMAS, 2003b, p. 153).

A comunidade discursiva legitima o Direito, sendo que o modelo procedimental da democracia tece as bases racionais para o desenvolvimento do discurso político democrático. Os fundamentos normativos do Estado Democrático de Direito resultam de processos deliberativos e decisórios que os fundadores iniciaram com a intenção de criar uma associação autônoma de participantes do Direito, livres e iguais, perquirindo quais direitos deverão ser atribuídos, reciprocamente, caso queiram regular legitimamente a convivência com os meios do Direito Positivo.

Os processos de formação democrática da opinião e da vontade, institucionalizados através de uma Constituição, atingem os mecanismos da integração social. Portanto, a política deliberativa depende em primeiro lugar da institucionalização dos processos comunicacionais, para em seguida surgir uma comunidade discursiva que possa assumir as funções próprias da cidadania, criando espaços de manifestação da vontade popular.

No modelo procedimental da democracia a sociedade civil é a base social de esferas públicas autônomas, havendo um deslocamento de pesos nas relações entre dinheiro, poder 
administrativo e solidariedade. Os processos de formação democrática da opinião e da vontade, institucionalizados através de uma Constituição, atingem os mecanismos da integração social, a exemplo do poder econômico e do poder administrativo, servindo-se do Direito. A racionalização discursiva das decisões do governo e da administração são vinculadas ao Direito e à lei. Por sua vez, a opinião pública, transformada em poder comunicativo segundo processos democráticos, embora não domine por si só o uso do poder administrativo, pode direcioná-lo, através das reivindicações populares. Contudo, a política deliberativa depende em primeiro lugar da institucionalização dos processos comunicacionais, para em seguida surgir uma comunidade discursiva que possa assumir as funções próprias da cidadania, criando espaços de manifestação da vontade popular.

No rastro da Kant, Habermas mantém a ideia da autolegislação de seres racionais, capazes de atingir a autonomia pessoal. A proposta de uma autolegislação estabelece um nexo interno entre razão e vontade, que se desenvolve na dimensão do tempo, como um processo histórico de erros e acertos. O imperativo categórico é reinterpretado em função da virada pragmática linguística, sendo que a liberdade depende da consideração simétrica da liberdade individual de cada um, que pode tomar posição dizendo sim ou não e somente encontra assentimento racional aquela norma que pode ser de interesse de toda e qualquer criatura. Uma vez que não há qualquer fundamentação transcendental para garantir pontos de partida a priori para o entendimento humano, as normas morais e jurídicas acordadas mediante o discurso racional, ocupam um espaço privilegiado, as primeiras compreendendo as regras do comportamento esperado pelo grupo social e as regras jurídicas necessárias à segurança e a previsibilidade das condutas. O critério de julgamento para aferir da pertinência ou não de determinado proferimento no espaço intersubjetivo do discurso é a justiça, que advém do princípio da democracia. A ideia central da democracia consiste em se atribuir a todos os atingidos igual direito à participação em processos coletivos de formação da vontade.

Na atitude da pessoa racional, que toma distância de si mesma, reflete-se, de modo geral, a racionalidade inerente à estrutura e ao procedimento da argumentação. Habermas tem se dedicado a esclarecer esse salto do saber ingênuo para um tipo de saber racional que possa ser justificado perante um suposto auditório da comunidade de interpretação ilimitada e que seriam os princípios plausíveis para a construção do ordenamento moral e jurídico. (HABERMAS, 1993, p. 112) 
O telos da linguagem é o entendimento, passando a razão a ser discursiva, pois prevalece a força do melhor argumento. As pretensões de validade são compartilhadas como verdades justificadas intersubjetivamente e assumem uma espécie de conotação transcendental, uma vez que os interlocutores devem aceitar a existência de um mundo idêntico para todos. No uso regular da linguagem, a pretensão de retitude ou adequação das normas é justificada, a partir das normas vigentes na sociedade. No momento em que uma pretensão se torna problemática, surge a necessidade de refazer o consenso, mediante a justificativa advinda de um discurso prático. Um acordo válido é aquele que encontra a concordância de todos em função da racionalidade de seus fundamentos mas, como pode vir a ser questionado futuramente, não merece a chancela de verdade universal e necessária, uma vez que é algo tido como verdade e se apresenta como válido para determinada comunidade discursiva, estando aberto a revisões, caso surjam melhores argumentos. A força geradora de consenso é dada pelo princípio da universalização “U”, que dá como certos os conteúdos dos proferimentos que todo e qualquer ser humano, desde que tenha entendimento, possa admitir como tal. Este princípio se efetiva mediante o princípio do discurso, situado para além dos jogos de linguagem.

O princípio do discurso introduz um elemento realista, na medida em que desloca as condições para uma formação política racional da opinião e da vontade: ele as retira do nível das motivações e decisões de atores ou grupos singulares e as transporta para o nível social de processos institucionalizados de resolução e de decisão. Os participantes da argumentação são exortados a antecipar em pensamento a autolegislação cooperativa que efetivamente se esperaria deles como sujeitos agindo no reino da liberdade. Para que o princípio do discurso assuma a figura jurídica é necessário que o código do direito, enquanto tal, esteja disponível para pessoas que, na qualidade de titulares de direitos subjetivos, fazem parte de uma associação de parceiros do direito, com pretensões jurídicas efetivas.

O Direito é o instrumento que carrega de forma abstrata as estruturas de reconhecimento recíproco existentes tanto entre conhecidos que interagem em contextos concretos do agir comunicativo, como a nível das interações anônimas entre estranhos, mediadas pelo sistema. A compreensão procedimentalista do direito tenta mostrar que os pressupostos comunicativos e as condições do processo de formação democrática da opinião e da vontade são as únicas fontes de legitimação do direito.

Somente podem pretender validade as leis jurídicas capazes de encontrar o assentimento de todos os parceiros do direito, num processo jurídico de normatização discursiva. Portanto, 
para que o Direito mantenha sua legitimidade, no que diz respeito a autonomia pública, é necessário que os cidadãos troquem seu papel de sujeitos privados do direito e assumam a perspectiva de participantes em processos de entendimentos políticos. As normas do direito só podem obrigar duradouramente quando os procedimentos que comandaram o seu surgimento forem reconhecidos como legítimos. Nesse momento de reconhecimento faz-se valer um agir comunicativo que, por assim dizer, aparece no outro lado do sistema de direito, no lado da formação democrática da vontade e da legislação política enquanto tal.

Portanto, Habermas entende a legitimidade do direito impositivo, como racionalidade procedimental que depende, primeiramente, de um arranjo comunicativo apropriado para a formação política racional da vontade do legislador e, num segundo momento, da interpretação construtiva da norma pelo aplicador do Direito.

Essa compreensão do Direito como meio para o disciplinamento das instituições políticas e das condutas humanas, sob o enfoque da racionalidade comunicativa permite um passo adiante na História da Democracia, recriando-se o espaço público da democracia direta, podendo-se avançar no caminho da emancipação política e fortalecendo-se a democracia, como sendo de fato, um governo do povo para o povo.

\section{CONSIDERAÇÕES FINAIS}

Não resta dúvida que o pensamento habermasiano contribui para a reflexão acerca da mudança de paradigma operado na contemporaneidade, possibilitando uma melhor compreensão da esfera política e dos direitos humanos, uma vez que a soberania popular é o fator que define o regime democrático. Este se caracteriza por ser o governo do povo, que se submete às leis que atribui a si próprio, no exercício da autonomia.

Hoje, com os meios de comunicação desenvolvidos pela tecnologia da informática, há um fácil acesso de todos às informações. A era virtual implica na possibilidade de maior participação das pessoas. Abre-se a possibilidade a um retorno às origens da democracia, cujo poder era efetivamente exercido pelos cidadãos, que na Praça Pública decidiam o próprio destino e davam forma ao mundo comum.

Nesse contexto, o presente artigo buscou no referencial teórico de Jürgen Habermas as bases filosóficas para compreender a ruptura da tradição e a formulação de um novo paradigma, o intersubjetivo, que desloca do indivíduo a capacidade de intuir a lei universal e necessária, que todo e qualquer cidadão, posto que racional, estaria apto a intuir a priori, para enfocar o 
espaço da linguagem e da comunicação, o intersubjetivo dos sujeitos capazes de falar e agir. Há um deslocamento do indivíduo para a comunidade discursiva, superando Habermas o logocenrtismo e o distanciamento entre a episteme e a práxis. As regras de condutas serão articuladas a posteriori, e representam a concepção de mundo de determinada comunidade.

A sua Teoria da Ação Comunicativa provoca a reflexão acerca da função da integração social e dos respectivos planos de ação conjunta, a partir da linguagem compartilhada. A produção do conhecimento é socializada e a conversa travada no espaço discursivo diz respeito ao bem viver de toda e qualquer criatura humana. A Teoria da Ação Comunicativa contribui para a compreensão dos processos de interação e distingue o tipo de ação estratégica, aquela voltada aos interesses pessoais do cotidiano da vida, da ação comunicativa, que diz respeito aos interesses coletivos que se desenrolam no espaço público do aparecimento do poder político dos cidadãos. Habermas fornece as bases conceituais para uma conscientização a respeito da razão comunicativa e de suas possibilidades políticas.

Esse paradigma intersubjetivo acarreta o primado do social. Depara-se com a evolução social sob o prisma do desenvolvimento pessoal de cada um, a partir das imagens do mundo particular, dos sistemas de crenças morais, desembocando nos sistemas jurídicos, que garantem a previsibilidade das condutas e a sanção para aqueles que desejam abrir exceções para si mesmos, no sentido de obter vantagens indevidas.

Ao estabelecer as regras para o debate discursivo, Habermas possibilita o desenvolvimento de arenas onde o debate pode vir a ser profícuo, no sentido de uma comunidade que toma consciência dos pontos controvertidos e busca propor soluções. Desta forma, o poder político dos cidadãos na democracia pode surgir, não como um fogo fátuo, nos momentos revolucionários, conforme identificado por Arendt, mas como real e empírico. O conceito de aprendizagem está presente nessa visão pragmática da linguagem e os participantes do discurso podem aprender mediante a participação neste espaço discursivo.

Se democracia se configura como o governo do povo pelo povo, é necessário que cada cidadão tome consciência da sua co-responsabilidade pela construção do mundo comum. A fim de que o povo deixe de ser manobrado pela elite pensante, que escreve as leis idealizadas no mundo do “dever ser”, conforme Kelsen, compete a cada um buscar a participação na arena pública, trazendo o empírico, o mundo do “ser”, como base para as decisões políticas e jurídicas. 
Desta forma a Filosofia de Habermas muito tem a contribuir para esse processo de aprendizagem, uma vez que tece as bases racionais para o desenvolvimento do discurso político democrático. O conteúdo deste discurso é variável e surge da interação que brota da comunidade discursiva. No entanto, a fim de que esta comunidade não se descaracterize e tome a forma de outros tipos de regimes políticos, o princípio da democracia e o princípio do discurso são correlatos. Este último se desenrola a partir dos procedimentos próprios do processo democrático, garantidos por normas constitucionais. Na interpretação do republicanismo, a autonomia política dos cidadãos incorpora-se na auto-organização de uma comunidade que cria as suas próprias leis e somente estas serão os limites das liberdades democráticas.

\section{REFERÊNCIAS}

ARENDT, Hannah. A Condição Humana. 8. ed. São Paulo: Companhia das Letras, 1998.

HABERMAS, JÜRGEN. Passado como Futuro. Rio de Janeiro: Tempo Brasileiro, 1993. 112 p.

. Direito e Democracia. Entre facticidade e validade. vol. I. Tradutor Flávio Beno Siebeneichler. Rio de Janeiro: Tempo Brasileiro, 1997a. 354 p.

Direito e Democracia. Entre facticidade e validade. vol. II. Tradutor Flávio Beno Siebeneichler. Rio de Janeiro: Tempo Brasileiro, 1997b. 352 p.

O Discurso Filosófico da Modernidade. Doze Lições. Tradutor Luiz Sérgio Repa; Rodnei Nascimento. São Paulo: Martins Fontes, 2002. 540 p.

. O Estado Democrático de Direito - Uma amarração paradoxal de princípios contraditórios? In: Era das Transições. Tradutor Flávio Beno Siebeneichler. Rio de Janeiro: Tempo Brasileiro, 2003. 
. Consciência Moral e Agir Comunicativo. Tradutor Guido Antônio de Almeida. Rio de Janeiro: Tempo Brasileiro, 2003a. 236 p.

. Era das Transições. Tradutor Flávio Beno Siebeneichler. Rio de Janeiro: Tempo Brasileiro, 2003b.

HABERMAS, Jürgen. A Ética da Discussão e a Questão da Verdade. São Paulo: Martins Fontes, 2004. 69 p.

Pensamento Pós-Metafísico. Tradutor Lumir Nahodil. Coimbra: Almedina, 2004a. 276 p.

Verdade e Justificação. Ensaios Filosóficos. Tradutor Milton Camargo Moto. São Paulo: Loyola; 2004b. p. 330.

. A Inclusão do Outro. Estudos de Teoria Política. Sperber, G. Soethe, PA. Tradutores Paulo Astor Soethe; Milton Camargo Mota. 3. ed. São Paulo: Loyola, 2007. 404p.

HUME, David. Uma Investigação sobre os princípios da Moral. Tradutor José Oscar de Almeida Marques. Campinas: Editora da Unicamp, 1995.

KANT, Immanuel. A Metafísica dos Costumes. Tradutor Edson Bini. 1. ed. São Paulo: Edipro - Edições Profissionais Ltda, 2003.

. Crítica da Faculdade do Juízo. 2. ed. Rio: Forense, 2002a.

. Crítica da Razão Prática. Tradutor Valerio Rohden. São Paulo: Martins Fontes, 2002b.

Fundamentação da Metafísica dos Costumes. Tradutor Paulo Quintela.Lisboa: Edições 70, [19--?].

KELSEN, Hans. Teoria Pura do Direito. 6. ed. Tradutor João Baptista Machado. São Paulo: Martins Fontes, 2003. p.427 p. 